European Psychiatry

www.cambridge.org/epa

\section{Original Article}

Cite this article: Dubreucq J, Plasse J, Gabayet F, Faraldo M, Blanc O, Chereau I, Cervello S, Couhet G, Demily C, GuillardBouhet N, Gouache B, Jaafari N, Legrand G, Legros-Lafarge E, Pommier R, Quilès C, Straub $D$, Verdoux $H$, Vignaga $F$, Massoubre $C$, REHABAse Network, Franck N (2020). Selfstigma in serious mental illness and autism spectrum disorder: Results from the REHABase national psychiatric rehabilitation cohort. European Psychiatry, 63(1), e13, 1-9 https://doi.org/10.1192/j.eurpsy.2019.12

Received: 20 September 2019

Revised: 21 October 2019

Accepted: 28 October 2019

\section{Key words:}

Self-stigma; serious mental illness; autism spectrum disorders; prevalence; psychiatric rehabilitation

\section{Author for correspondence:}

J. Dubreucq,

E-mail: jdubreucq@ch-alpes-isere.fr

\title{
Self-stigma in serious mental illness and autism spectrum disorder: Results from the REHABase national psychiatric rehabilitation cohort
}

\author{
J. Dubreucq ${ }^{1,2,3,4}$, J. Plasse ${ }^{5,6}$, F. Gabayet ${ }^{2,3}$, M. Faraldo ${ }^{2,3}$, O. Blanc B $^{3,16}$, \\ I. Chereau ${ }^{3,16}$, S. Cervello ${ }^{1,5,6}$, G. Couhet $^{8}$, C. Demily ${ }^{1,9}$, N. Guillard-Bouhet ${ }^{10}$, \\ B. Gouache ${ }^{2}$, N. Jaafari ${ }^{10}$, G. Legrand ${ }^{7}$, E. Legros-Lafarge ${ }^{11}$, R. Pommier ${ }^{12}$, \\ C. Quilès ${ }^{13}$, D. Straub ${ }^{14}$, H. Verdoux ${ }^{13}$, F. Vignaga ${ }^{15}$, C. Massoubre ${ }^{12}$, \\ REHABAse Network ${ }^{6}$ and N. Franck ${ }^{1,5,6}$
}

\begin{abstract}
${ }^{1}$ Centre de Neurosciences Cognitive, UMR 5229, CNRS \& Université Lyon 1, Lyon, France; ${ }^{2}$ Centre Référent de Réhabilitation Psychosociale et de Remédiation Cognitive (C3R), Centre Hospitalier Alpes Isère, Grenoble, France; ${ }^{3}$ Fondation FondaMental, Créteil, France; ${ }^{4}$ Réseau Handicap Psychique, Grenoble, France; ${ }^{5}$ Centre Référent Lyonnais de Réhabilitation Psychosociale CL3R, Centre Hospitalier Le Vinatier, Lyon, France; ${ }^{6}$ Centre Ressource de Réhabilitation Psychosociale et de Remédiation Cognitive, Hôpital Le Vinatier, UMR 5229, CNRS \& Université Lyon 1, Université de Lyon, Lyon, France; ${ }^{7}$ Centre Hospitalier Sainte Marie de Clermont Ferrand, 63037 Clermont-Ferrand Cedex 1, France; ${ }^{8}$ Centre Référent de Réhabilitation Psychosociale C2RP Nouvelle-Aquitaine Sud, Pôle de Réhabilitation Psychosociale, Centre de la Tour de Gassies, Bruges, France; ${ }^{9}$ Centre de Référence Maladies Rares Génopsy, Centre Hospitalier Le Vinatier, UMR 5229, CNRS \& Université Lyon 1, Université de Lyon, Lyon, France; ${ }^{10}$ CREATIV \& URC Pierre Deniker, CH Laborit, Poitiers, France; ${ }^{11}$ Centre Référent de Réhabilitation Psychosociale de Limoges C2RL, CH Esquirol, Limoges, France; ${ }^{12}$ REHALise, CHU de Saint-Etienne, Saint-Priest-en-Jarez, France; ${ }^{13}$ Centre Référent de Réhabilitation Psychosociale C2RP Nouvelle Aquitaine Sud, Pôle Universitaire de Psychiatrie Adulte, Centre Hospitalier Charles Perrens, Bordeaux \& Univ. Bordeaux, INSERM, Bordeaux Population Health Research Center, Team Pharmacoepidemiology, UMR 1219, 33000 Bordeaux, France; ${ }^{14}$ Centre de Réhabilitation Psychosociale, Centre Hospitalier de Roanne, Roanne, France; ${ }^{15}$ Dispositif de Soins de Réhabilitation Psychosociale, Centre Psychothérapeutique de l'Ain, Bourg-en-Bresse, France and ${ }^{16} \mathrm{CMP}$ B, CHU, EA 7280 Faculté de Médecine, Université d'Auvergne, BP 6963003 Clermont-Ferrand Cedex 1, France
\end{abstract}

\begin{abstract}
Background. Self-stigma is a major issue in serious mental illness (SMI) and is negatively associated with patient outcomes. Most studies have been conducted in schizophrenia (SZ). Less is known about self-stigma in other SMI and autism spectrum disorder (ASD). The objectives of this study are: (i) to assess the frequency of self-stigma in a multicentric nonselected psychiatric rehabilitation SMI and ASD sample; and (ii) to investigate the correlates of elevated self-stigma in different SMI conditions and in ASD.

Methods. A total of 738 SMI or ASD outpatients were recruited from the French National Centers of Reference for Psychiatric Rehabilitation cohort (REHABase). Evaluations included sociodemographic data, illness characteristics, and standardized scales for clinical severity, quality of life, satisfaction with life, wellbeing, personal recovery, a large cognitive battery, and daily functioning assessment.

Results. $31.2 \%$ of the total sample had elevated self-stigma. The highest prevalence (43.8\%) was found in borderline personality disorder and the lowest (22.2\%) in ASD. In the multivariate analysis, elevated self-stigma was best predicted by early stages of personal recovery (moratorium, $p=0.001, \mathrm{OR}=4.0$ [1.78-8.98]; awareness, $p=0.011$, $\mathrm{OR}=2.87$ [1.28-6.44]), history of suicide attempt $(p=0.001, \mathrm{OR}=2.27[1.37-3.76])$, insight $(p=0.002, \mathrm{OR}=1.22[1.08-1.38])$, wellbeing $(p=0.037, \mathrm{OR}=0.77[0.60-0.98])$, and satisfaction with interpersonal relationships $(p<0.001, \mathrm{OR}=0.85[0.78-0.93])$.

Conclusions. The present study has confirmed the importance of addressing self-stigma in SMI and ASD patients enrolled in psychiatric rehabilitation. The effectiveness of psychiatric rehabilitation on self-stigma and the potential mediating effects of changes in self-stigma on treatment outcomes should be further investigated.
\end{abstract}

(c) The Author(s) 2020. This is an Open Access article, distributed under the terms of the Creative Commons Attribution licence (http:// creativecommons.org/licenses/by/4.0/), which permits unrestricted re-use, distribution, and reproduction in any medium, provided the original work is properly cited.

EUROPEAN PSYCHIATRIC ASSOCIATION

\section{Introduction}

Many members of the general public endorse negative stereotypes about Serious Mental Illness (SMI) or autism spectrum disorders (ASD). These include expectations of violence and an inability to work or to live in society that can lead to social distancing and rejection. Although less stigmatized than schizophrenia (SZ), ASD was associated with dangerousness to self and an inability to work in over $20 \%$ of the 1,000 respondents in a 2012 French population survey [1]. Most people with SMI are aware of these stereotypes and expect to be discriminated against 
by other people because of their condition $(69.4 \%$ of the 1,229 participants with $\mathrm{SZ}$ and $71.6 \%$ of the 1,182 participants with mood disorders in the GAMIAN-Europe study had high perceived stigma [2,3]). Self-stigma-or internalized stigma (IS)-occurs when someone accepts the negative stereotypes about SMI or ASD as a true description of him/herself [4]. IS refers to the process wherein a person's previously held social identity (defined by social roles such as son, brother, sister, friend, employee, or potential partner) is progressively replaced by a devalued and stigmatized view of oneself. IS is highly prevalent in Europe $(41.7 \%$ in SZ, $21.7 \%$ in mood disorders [1,2]) and the United States $(36.1 \%$ out of 144 people with SMI [5]). According to the "illness identity model" [6], IS can have pervasive effects on recovery-related outcomes, including self-esteem, hopefulness, wellbeing, motivation to achieve personal life goals, social interaction, employment, and symptom severity [7-10]. Individuals with elevated self-stigma report more dysfunctional attitudes, social withdrawal, depressive symptoms, and increased suicidal ideation $[6,11,12]$. Several studies also support that high insight into illness directly predicts and compounds the effects of self-stigma on depression $[11,13,14]$. Impaired cognitive functioning, metacognition, and social cognition predict increased self-stigma [14-17].

Stigma studies have mostly targeted individuals with SZ (54.3\% out of 127 articles; Livingston and Boyd [18]; 42.3\% of 220 articles in a recent review [19]), SMI (40\% of 220 articles [19]) or mood disorders (bipolar disorder [BD] 5\% and major depression [MDD] $5.7 \%$ of 220 articles [19]). Considerably less is known about IS in borderline personality disorder (BPD), anxiety disorders, and ASD. Some studies found that self-stigma was higher in BPD than in SZ (Internalized Stigma of Mental Illness [ISMI] mean total score = $2.43 \mathrm{BPD}$ vs. $2.34 \mathrm{SZ}$ [20]) and lower in anxiety disorders (ISMI total score ranging from 1.98 to 2.24 in Europe [19]) or ASD (ISMI total $=1.93,15.7 \%$ out of 149 participants showing elevated selfstigma [21]). Self-stigma was also associated with increased psychiatric symptoms, reduced hope, and lower treatment adherence in anxiety disorders or BPD $[20,22,23]$. The correlates of IS in ASD are still unknown. Several potential predictors were identified, the most significant of which were insight into illness, hopelessness, impaired cognitive functioning, avoidant coping strategies, stigma stress, perceived stigma, and psychiatric symptoms [19]. Contrasting results were found for occupational status, psychiatric diagnosis, and illness duration. Individual studies identified other factors such as parenting status or decreased wellbeing as potential predictors of self-stigma [24,25]. Few studies investigated self-stigma within the context of psychiatric rehabilitation or recovery-oriented practices (7.7\% of 220 articles [19]). Recovery-oriented interventions have shown preliminary effectiveness on self-stigma [26-29]. Self-stigma was associated with worse treatment outcomes during vocational rehabilitation [30]. However, the prevalence of IS in patients attending to psychiatric rehabilitation and its effects on therapeutic outcomes remain largely unknown. To the best of our knowledge, only one study, of a small sample of SZ patients, has investigated selfstigma in France, finding moderate levels of IS ( $n=62$, ISMI total score $=2.23$ [31]). The frequency of elevated self-stigma in SMI or ASD is still unknown.

To sum up, self-stigma is a major issue in SMI and is associated with poor clinical and functional outcomes. Its frequency in SZ or mood disorders is high in European countries. Considerably less is known about self-stigma in other SMI and in ASD and there are no data on IS prevalence in France. Previous research indicates that insight into illness, psychiatric symptoms, and cognitive functioning could predict the level of self-stigma. Other variables from individual studies such as parenting status or wellbeing might predict IS but these results need to be confirmed. The correlates of IS in BPD, anxiety disorders and ASD remain largely unknown.

The objectives of the present study were: (i) to assess the frequency of self-stigma in a multicentric nonselected psychiatric rehabilitation SMI and ASD sample; and (ii) to investigate the correlates of elevated self-stigma in different SMI conditions and in ASD.

\section{Materials and Methods}

\section{Study population}

The REHABase cohort is made up of patients from a French network of psychiatric rehabilitation centers that has been extensively described in a previous article [32]. Patients are referred to these centers by their general practitioner or psychiatrist, who remains in charge of routine care and treatment. The inclusion criteria are: (i) a diagnosis of SMI (i.e., SZ, BD, BPD, MDD, or severe anxiety disorders, according to the SAMSAH 2013 definition [33]) or ASD (DMS-5 criteria [34]); (ii) a score below the cut-off scores for social recovery according to Jääskeläinen et al. in 2013 (a score of less than 61 on the Global Assessment of Functioning (GAF) Scale [35]). A comprehensive clinical, functional, and cognitive assessment is performed to establish the individual's strengths and weaknesses, autonomy, and occupational level. Therapeutic tools are selected based on the participant's personal life goals as part of an individualized psychiatric rehabilitation action plan. The action plan can include psychoeducation, joint crisis plans, cognitive remediation, cognitive behavior therapy, social skills training, peer-delivered interventions, and supported employment [32]. Follow-up is planned to last for 2 to 3 years. Evaluations are scheduled at baseline, annually, and after the action plan is completed. The action plan can begin before the evaluation when clinically relevant to support patient's engagement in mental health care or psychiatric rehabilitation. This is for instance the case for strengths-based case management in early psychosis and supported employment, housing, or parenting. Two thousand and fifty-three patients were included in the eight REHABase sites between January 2016 and April 2019. Seven hundred and thirtyeight $(35.9 \%)$ were effectively evaluated at the time of extraction. The study obtained the authorizations required under French legislation (French National Advisory Committee for the Treatment of Information in Health Research, 16.060bis; French National Computing and Freedom Committee, DR-2017-268). All participants gave their informed consent.

\section{Site selection and training}

Site selection and training have been described in a previous article [32]. Since this first study, three new sites have joined the REHABase network. The eight sites (Lyon, Grenoble, Saint-Etienne, Limoges/Poitiers, Bordeaux, Clermont-Ferrand, Roanne, and Bourg-en-Bresse) opened in France were already actively involved in the treatment of patients with SMI (pharmacological and nonpharmacological), as well as research on psychiatric rehabilitation and recovery-oriented practices. Each center has accepted and been trained to use the same package of assessment tools for the baseline visit and follow-up. Clinical team members have regular group meetings to monitor quality control and ensure good inter-rater reliability. 


\section{Data collected}

General information on education, marital status, economic status, illness onset and trajectory and comorbidities was recorded. Selfstigma was assessed using the ISMI Scale [2,36], a 29-item selfreport measure designed to assess people's personal experience of stigma related to mental disorders and is rated on a 4-point Likert Scale. Items are summed to provide a mean total score and five subscale scores (alienation or feeling of being a devalued member of society; stereotype endorsement or agreement with negative attitudes about SMI; experience of discrimination; and social withdrawal as a coping strategy and stigma resistance). Stigma resistance is generally excluded because of poor correlations with other subscales [37]. A higher score reflects a higher level of selfstigma. A score above 2.5 indicates a moderate to high level of selfstigma [2,3]. Satisfaction in four life dimensions (social, familial, and intimate relationships, occupational status) was measured using visual analogue scales and a structured interview adapted from the Client Assessment of Strengths, Interests, and Goals (CASIG) [38]. Illness severity was assessed using the Positive and Negative Syndrome (PANSS) [39] and the Clinical Global Impression (CGI) [40] scales. Insight and treatment adherence were measured with self-reported measures (Birchwood Insight Scale [BIS] [41]; Medication Adherence Rating Scale [MARS] [42]). General functioning was measured with the GAF Scale [43]. Quality of Life was evaluated with the self-reported Subjective Quality of Life Scale (S-QoL) [44] and wellbeing using the WarwickEdinburgh Mental Well-being Scale (WEMWBS) [45]. Selfesteem was assessed with the Self-Esteem Rating Scale-Short Form (SERS-SF) [46] and personal recovery was measured using the self-reporting Stages of Recovery Instrument (STORI) [47]. Baseline neuropsychological cognitive assessments include the Wechsler Adult Intelligence Scale-4th edition (WAIS-IV) [48] subscale assessing short-term and working memory, the California Verbal Learning Test [49] or RL/RI-16 [50] for global verbal memory, $\mathrm{d} 2-\mathrm{R}$ for selective attention, concentration and speed of processing [51] and the shopping test [52] or Six Element Test [53] for planning abilities. Theory of mind was assessed using the Movie for the Assessment of Social Cognition [54] and attribution style with the Ambiguous Intentions and Hostility Questionnaire (AIHQ) [55].

\section{Statistical analysis}

Data are presented as the mean and SD for continuous variables and number and percentage for categorical variables. A one-way analysis of variance was performed and the $p$-values adjusted for multiple comparisons using Tukey's method. The internal consistency of the ISMI total scale and subscales was measured using Cronbach's alpha $(\alpha)$.

Patients' baseline characteristics were analyzed to identify factors associated with a high level of self-stigma. Categorical variables were analyzed using chi-square analysis or Fisher's exact test as appropriate, and continuous variables were analyzed using Student's $t$ test or Wilcoxon's test for non-normal variables. Logistic regression was used to calculate OR with $95 \%$ CI. Finally, a multivariate logistic regression with stepwise selection was performed on all predictors to investigate the factors independently associated with the level of selfstigma. The collinearity was checked using the variance inflation factor. $p$-Values $<0.05$ were considered significant. All statistical analyses were performed using R (R Foundation for Statistical Computing, Vienna, Austria; https://www.R-project.org/) [56].

\section{Results}

Seven hundred and thirty-eight clinically stabilized patients were recruited from the REHABase network. They were included in this cohort study between January 2016 and April 2019. SZ was the most common diagnosis with 466 patients $(63.1 \%)$. Other diagnoses were BD $(117,15.9 \%)$, BPD $(64,8.7 \%)$, ASD (45, 6.1\%), MDD $(27,3.7 \%)$, and anxiety disorders $(19,2.5 \%)$. The included patients were mostly men $(500,67.8 \%)$, with a mean duration of illness of $11.5(\mathrm{SD}=8.7)$ years and a mean baseline PANSS total score of 66.4 $(\mathrm{SD}=19.1)$. Baseline sample characteristics are shown in Table 1. There were significant differences according to participant's psychiatric diagnosis (data not shown). The analysis of variance showed that diagnosis had a significant effect on $\operatorname{GAF}(F(5,514)$ $=3.71, p=0.03$ ). The post hoc analyses indicated that global functioning was lower in SZ than in BD $(\operatorname{diff}=-6.3, p=0.02)$. A significant effect was also found on subjective QoL $(F(5,649)=$ $4.64, p<0.001)$. SQoL was significantly lower in anxiety disorders (diff $=-13.5, p=0.02)$ and BPD (diff $=-8.4, p=0.01)$ compared with SZ. Wellbeing $(F(5,699)=3.28, p=0.006)$ and satisfaction with interpersonal relationships $(F(5,569)=5.48, p<0.001)$ were significantly lower in BPD compared with $\mathrm{SZ}$ and $\mathrm{BD}$ (diff $=-0.6$ for WEMWBS and diff $=-2$ for satisfaction with interpersonal relationships).

\section{Frequency of elevated self-stigma}

The internal consistency for the 24-item ISMI was $\alpha=0.90$. The stigma resistance subscale had an internal consistency of $\alpha=0.49$. The following values were found for the other four subscales: alienation $\alpha=0.81$, stereotype endorsement $\alpha=0.69$, experience of discrimination $\alpha=0.78$, social withdrawal $\alpha=0.78$. Table 2 presents the results of grouping ISMI total and subscale scores for the total sample and per diagnosis, using minimal-low and moderatehigh self-stigma categories. Elevated self-stigma was found in $31.2 \%$ of the total sample $(29.8 \%$ in SZ, $29.9 \%$ in BD, $40.7 \%$ in MDD, $42.1 \%$ in anxiety disorders, $43.8 \%$ in BPD and $22.2 \%$ in ASD). The highest extent of self-stigma was found in BPD (mean ISMI total score $=2.36$ ) and the lowest in ASD (2.13).

\section{Correlates of elevated self-stigma}

Table 3 presents the results of the univariate analyses for the correlates of elevated self-stigma. Significant associations were found with female gender $(p=0.095 ; \mathrm{OR}=1.32[0.95-1.83])$ and older age at the time of admission $(p=0.002$; OR $=1.03$ [1.01-1.04]). Elevated self-stigma was positively associated with psychiatric comorbidities $(p=0.05, \mathrm{OR}=1.46[1.00-2.12])$, history of suicide attempt $(p<0.001$, $\mathrm{OR}=2.30$ [1.64-3.22]), insight (BIS, $p<0.001, \mathrm{OR}=1.27[1.17-1.38]$ ) and clinical severity (CGI, $p<0.001, \mathrm{OR}=1.54$ [1.28-1.87]). Elevated self-stigma was negatively associated with satisfaction with interpersonal $(p<0.001, \mathrm{OR}=0.79$ [0.73-0.84]), familial $(p<0.001, \mathrm{OR}=0.85$ $[0.79-0.91])$, and intimate relationships $(p<0.001, \mathrm{OR}=0.88[0.83-$ $0.93]$ ). Negative associations were found between elevated self-stigma and wellbeing (WEMWBS total score, $p<0.001$, OR $=0.54[0.47-$ $0.62]$ ) or treatment adherence (MARS, $p<0.001$; OR $=0.84[0.77-$ $0.92])$. Elevated self-stigma was negatively associated with personal recovery $(p<0.001)$. Compared with participants in the growth stage of personal recovery, those in earlier stages showed significantly higher levels of self-stigma (moratorium, $\mathrm{OR}=9.83$ [5.73-17.33]; awareness, $\mathrm{OR}=5.49$ [3.08-9.97]; preparation, $\mathrm{OR}=4.00 \quad[2.06-$ 7.79]; rebuilding, $\mathrm{OR}=2.34$ [1.34-4.15]). No significant correlations 
Table 1. Patient characteristics

\begin{tabular}{|c|c|c|}
\hline & & $\begin{array}{l}\text { All patients } \\
(n=738)\end{array}$ \\
\hline \multirow[t]{2}{*}{ Gender $(n=738)$} & Male & $500(67.8)$ \\
\hline & Female & $238(32.2)$ \\
\hline $\begin{array}{l}\text { Age at the time of } \\
\text { admission }(n=738)\end{array}$ & Mean (SD) & $33.2(10.1)$ \\
\hline \multirow[t]{3}{*}{ Education level $(n=726)$} & Primary/secondary school & $137(18.9)$ \\
\hline & High school & $365(50.3)$ \\
\hline & University & $224(30.8)$ \\
\hline \multirow[t]{3}{*}{ Housing status $(n=729)$} & Personal accommodation & $362(49.7)$ \\
\hline & Family accommodation & $282(38.7)$ \\
\hline & $\begin{array}{l}\text { Others (supervised } \\
\text { apartment, household) }\end{array}$ & $85(11.6)$ \\
\hline \multirow{3}{*}{$\begin{array}{l}\text { Occupational status } \\
\qquad(n=723)\end{array}$} & Without income & $149(20.6)$ \\
\hline & Competitive/sheltered work & $62(8.6)$ \\
\hline & $\begin{array}{l}\text { Unemployment/disability } \\
\text { benefits }\end{array}$ & $512(70.8)$ \\
\hline \multirow[t]{2}{*}{ Marital status $(n=728)$} & Single & $625(85.9)$ \\
\hline & In a couple & $103(14.1)$ \\
\hline \multirow{2}{*}{$\begin{array}{l}\text { Number of children } \\
\qquad(n=722)\end{array}$} & Without child & $606(83.9)$ \\
\hline & At least one child & $116(16.1)$ \\
\hline \multirow[t]{2}{*}{ Legal protection $(n=721)$} & Without & $613(85.0)$ \\
\hline & With & $108(15.0)$ \\
\hline
\end{tabular}

Values are mean (SD) or $n(\%)$.

were found with age of onset, educational level, housing status, occupational status, duration of psychiatric hospitalizations, intimate relationships, parenting status, and cognitive functioning.

In the multivariate analysis (Table 4), elevated self-stigma was associated with early stages of personal recovery (moratorium, $p=0.001, \mathrm{OR}=4.0[1.78-8.98]$; awareness, $p=0.011, \mathrm{OR}=2.87$ $[1.28-6.44])$, history of suicide attempt $(p=0.001, \mathrm{OR}=2.27$ [1.37-3.76]), insight $(p=0.002, \mathrm{OR}=1.22[1.08-1.38])$, wellbeing (WEMWBS, $p=0.037$, OR $=0.77[0.60-0.98]$ ) and satisfaction with interpersonal relationships $(p<0.001, \mathrm{OR}=0.85[0.78-0.93])$.

\section{Discussion}

To the best of our knowledge, this study is the first to assess the prevalence of self-stigma in a multicentric nonselected psychiatric rehabilitation SMI and ASD sample. As expected, the prevalence of self-stigma in France was high (31.3\%). The highest proportion of individuals with elevated self-stigma was found in BPD (43.8\%) and the lowest in ASD (22.2\%). Self-stigma was higher in BD, MDD, and anxiety disorders compared with SZ. Female gender and older age at the time of admission predicted self-stigma in contrast with other socio-demographic variables (education level, occupational status, housing status, intimate relationships, parenting status). Illness duration, the number of psychiatric hospitalizations, a history of suicide attempt, and a greater insight into illness were significant correlates of the level of self-stigma. Other variables such as psychiatric diagnosis, age of onset, the duration of psychiatric hospitalizations and cognitive functioning did not yield significant associations. Self-stigma positively correlated with symptom severity, clinical severity, and psychiatric comorbidities. Elevated self-stigma was negatively associated with treatment adherence, psychosocial functioning, self-esteem, QoL, wellbeing, and satisfaction with different life domains and personal recovery. Self-stigma and personal recovery were strongly correlated in the multivariate model. Individuals in the early stages of personal recovery (moratorium or awareness) had a fourfold and a threefold risk, respectively, of presenting an elevated level of self-stigma compared with individuals in the growth stage. Other significant predictors of self-stigma in the multivariate model were a history of suicide attempt (twofold risk of elevated selfstigma), a higher insight into illness (risk $\times 1.22$ ) and decreased wellbeing (risk $\times 1.3)$ and satisfaction with interpersonal relationships $($ risk $\times 1.18)$.

The prevalence of elevated self-stigma for SMI is comparable with other studies conducted in other countries across the world (weighted proportion $=31.5$ of the 5,457 participants included in 27 studies [19]). Self-stigma in SZ was within the average for European countries (mean IS $=2.16$ in 10 studies [19]), elevated self-stigma being less prevalent than in Brohan et al. (41.7\%, mean IS $=2.40$ [2]). The important country-related \%variations in this study may explain these differences (from $15.2 \%$ in Sweden to $50 \%$ in Croatia [2]). Elevated self-stigma in SZ was less frequent compared with South Asia (weighted prevalence $=36.8 \%$ [19]), SouthEast Asia (36.6\%), Africa (39.4\%), North America (44.2\%), and South America (38.6\%) [57]. Cultural factors and country or setting-related differences might explain these variations [19]. Selfstigma in mood disorders was higher compared with other

Table 2. Internalized stigma in psychiatric disorders in the study sample

\begin{tabular}{|c|c|c|c|c|c|c|c|}
\hline \multirow[b]{2}{*}{ Population $(n=738)$} & \multicolumn{2}{|c|}{ Full scale-mean (SD) } & \multicolumn{5}{|c|}{ Subscales-mean (SD) } \\
\hline & $\begin{array}{l}\text { With stigma } \\
\text { resistance }\end{array}$ & $\begin{array}{l}\text { Without stigma } \\
\text { resistance }\end{array}$ & Alienation & $\begin{array}{l}\text { Stereotype } \\
\text { endorsement }\end{array}$ & $\begin{array}{l}\text { Discrimination } \\
\text { experience }\end{array}$ & $\begin{array}{l}\text { Social } \\
\text { withdrawal }\end{array}$ & $\begin{array}{l}\text { Stigma } \\
\text { resistance }\end{array}$ \\
\hline All diagnoses & $2.25(0.45)$ & $2.2(0.51)$ & $2.48(0.69)$ & $1.9(0.48)$ & $2.17(0.65)$ & $2.31(0.65)$ & $2.54(0.51)$ \\
\hline Autism spectrum disorder (ASD; $n=45$ ) & $2.2(0.42)$ & $2.13(0.48)$ & $2.39(0.65)$ & $1.74(0.42)$ & $2.18(0.65)$ & $2.29(0.65)$ & $2.48(0.52)$ \\
\hline Schizophrenia (SZ; $n=466$ ) & $2.22(0.46)$ & $2.18(0.51)$ & $2.42(0.7)$ & $1.9(0.49)$ & $2.15(0.64)$ & $2.27(0.63)$ & $2.56(0.51)$ \\
\hline Bipolar disorder (BD; $n=117)$ & $2.25(0.44)$ & $2.2(0.53)$ & $2.59(0.67)$ & $1.85(0.47)$ & $2.22(0.68)$ & $2.25(0.67)$ & $2.52(0.53)$ \\
\hline Major depressive disorder (MDD; $n=27$ ) & $2.31(0.49)$ & $2.29(0.56)$ & $2.61(0.78)$ & $1.95(0.53)$ & $2.21(0.69)$ & $2.44(0.67)$ & $2.58(0.53)$ \\
\hline Anxiety disorders $(n=19)$ & $2.38(0.48)$ & $2.35(0.56)$ & $2.87(0.71)$ & $1.97(0.44)$ & $2.15(0.74)$ & $2.44(0.68)$ & $2.44(0.38)$ \\
\hline $\begin{array}{l}\text { Borderline personality disorder } \\
\qquad \text { (BPD; } n=64)\end{array}$ & $2.38(0.42)$ & $2.36(0.47)$ & $2.65(0.62)$ & $2.05(0.42)$ & $2.23(0.59)$ & $2.55(0.68)$ & $2.52(0.48)$ \\
\hline
\end{tabular}


Table 3. Association between medical factors and quality of life with self-stigma in univariate logistic regression

\begin{tabular}{|c|c|c|c|c|c|c|}
\hline & & $\begin{array}{c}\text { All } \\
\text { patients } \\
(n=738)\end{array}$ & $\begin{array}{c}\text { Normal self- } \\
\text { stigma } \\
(n=508)\end{array}$ & $\begin{array}{c}\text { Elevated self- } \\
\text { stigma } \\
(n=230)\end{array}$ & $p$-Value & Odds ratio (univariate) \\
\hline \multirow[t]{6}{*}{ Diagnoses class (DSM5; $n=738$ ) } & Autism Spectrum Disorder (ASD) & $45(6.1)$ & $35(6.9)$ & $10(4.3)$ & 0.1 & \\
\hline & Schizophrenia (SZ) & $466(63.1)$ & $328(64.6)$ & $138(60.0)$ & & \\
\hline & Bipolar disorder (BD) & $117(15.9)$ & $82(16.1)$ & $35(15.2)$ & & \\
\hline & Major depressive disorder (MDD) & $27(3.7)$ & $16(3.1)$ & $11(4.8)$ & & \\
\hline & Anxiety disorders & $19(2.6)$ & $11(2.2)$ & $8(3.5)$ & & \\
\hline & Borderline personality disorder (BPD) & $64(8.7)$ & $36(7.1)$ & $28(12.2)$ & & \\
\hline Illness duration (years; $n=649$ ) & Mean (SD) & $11.5(8.7)$ & $10.8(8.3)$ & $13.1(9.3)$ & 0.001 & $1.03(1.01-1.05, p=0.002)$ \\
\hline \multirow[t]{2}{*}{ Psychiatric comorbidity $(n=629)$} & No & $465(73.9)$ & $333(76.2)$ & $132(68.8)$ & 0.05 & - \\
\hline & Yes & $164(26.1)$ & $104(23.8)$ & $60(31.2)$ & & $1.46(1.00-2.12, p=0.051)$ \\
\hline Number of previous admissions ( $n=667)$ & Mean (SD) & $3.2(3.6)$ & $3.1(3.5)$ & $3.6(3.8)$ & 0.04 & $1.04(0.99-1.08, p=0.105)$ \\
\hline Duration of hospitalization (in months; $n=589$ ) & Mean (SD) & $6.5(13.1)$ & $6.5(14.5)$ & $6.4(8.8)$ & 0.221 & $1.00(0.98-1.01, p=0.976)$ \\
\hline \multirow[t]{2}{*}{ Suicide attempt $(n=704)$} & No & $493(70.0)$ & $367(75.7)$ & $126(57.5)$ & $<0.001$ & - \\
\hline & Yes & $211(30.0)$ & $118(24.3)$ & $93(42.5)$ & & $2.30(1.64-3.22, p<0.001)$ \\
\hline Global Assessment of Functioning $(n=520)$ & Mean (SD) & $56.7(13.4)$ & $57.9(13.4)$ & $54.0(12.9)$ & $<0.001$ & $0.98(0.96-0.99, p=0.002)$ \\
\hline Clinical Global Impression $(n=516)$ & Mean (SD) & $4.1(1.1)$ & $4.0(1.1)$ & $4.5(0.9)$ & $<0.001$ & $1.54(1.28-1.87, p<0.001)$ \\
\hline $\begin{array}{l}\text { CASIG adaptation-satisfaction level with interpersonal } \\
\text { relationships }(n=575)\end{array}$ & Mean (SD) & $5.8(2.9)$ & $6.4(2.7)$ & $4.5(2.8)$ & $<0.001$ & $0.79(0.73-0.84, p<0.001)$ \\
\hline CASIG adaptation-satisfaction level with family relationships $(n=575)$ & Mean (SD) & $6.7(2.6)$ & $7.1(2.4)$ & $6.0(2.7)$ & $<0.001$ & $0.85(0.79-0.91, p<0.001)$ \\
\hline CASIG adaptation-satisfaction level with intimate relationships $(n=569)$ & Mean (SD) & $3.9(3.2)$ & $4.4(3.2)$ & $3.1(3.0)$ & $<0.001$ & $0.88(0.83-0.93, p<0.001)$ \\
\hline CASIG adaptation-satisfaction level with vocational status $(n=555)$ & Mean (SD) & $3.2(2.9)$ & $3.5(3.0)$ & $2.8(2.7)$ & 0.006 & $0.92(0.86-0.98, p=0.008)$ \\
\hline CASIG adaptation-satisfaction level with education $(n=574)$ & Mean (SD) & $5.2(2.9)$ & $5.5(2.8)$ & $4.6(3.0)$ & $<0.001$ & $0.90(0.85-0.96, p=0.001)$ \\
\hline SQoL18 total score (\% satisfaction) $(n=655)$ & Mean (SD) & $50.8(17.9)$ & $54.5(17.3)$ & $42.8(16.5)$ & $<0.001$ & $0.96(0.95-0.97, p<0.001)$ \\
\hline SERS total score $(n=630)$ & Mean (SD) & $1.6(20.7)$ & $9.0(18.4)$ & $-13.7(16.5)$ & $<0.001$ & $0.93(0.92-0.94, p<0.001)$ \\
\hline \multirow[t]{5}{*}{ Global Stage Of Recovery Instrument (max of stages) $(n=621)$} & 5-Growth & $199(32.0)$ & $174(41.0)$ & $25(12.7)$ & $<0.001$ & - \\
\hline & 1-Moratorium & $123(19.8)$ & $51(12.0)$ & $72(36.5)$ & & $9.83(5.73-17.33, p<0.001)$ \\
\hline & 2-Awareness & $93(15.0)$ & $52(12.3)$ & $41(20.8)$ & & $5.49(3.08-9.97, p<0.001)$ \\
\hline & 3-Preparation & $63(10.1)$ & $40(9.4)$ & $23(11.7)$ & & $4.00(2.06-7.79, p<0.001)$ \\
\hline & 4-Rebuilding & $143(23.0)$ & $107(25.2)$ & $36(18.3)$ & & $2.34(1.34-4.15, p=0.003)$ \\
\hline IS Birchwood total score $(n=634)$ & Mean (SD) & $8.8(2.5)$ & $8.4(2.6)$ & $9.6(2.1)$ & $<0.001$ & $1.27(1.17-1.38, p<0.001)$ \\
\hline Warwick-Edinburgh Mental Well-Being Scale ( $z$-score; $n=705)$ & Mean (SD) & $-1.2(1.3)$ & $-1.0(1.3)$ & $-1.9(1.1)$ & $<0.001$ & $0.54(0.47-0.62, p<0.001)$ \\
\hline Medication Adherence Rating Scale total score $(n=594)$ & Mean (SD) & $6.7(1.9)$ & $6.9(1.9)$ & $6.3(2.0)$ & $<0.001$ & $0.84(0.77-0.92, p<0.001)$ \\
\hline
\end{tabular}

Values are $n(\%)$ or mean (SD). Bold indicates $p$ value $<0.05$. 
Table 4. Multivariate logistic regression summary (with stepwise selection)

\begin{tabular}{|c|c|c|c|c|c|}
\hline \multirow[b]{2}{*}{ Predictors $(n=380)$} & \multicolumn{5}{|c|}{ Self-stigma level } \\
\hline & Estimate & Std. error & $p$-Value & Odds ratio & $95 \% \mathrm{Cl}$ for odds ratio \\
\hline (Intercept) & -2.91 & 0.70 & $<0.001$ & 0.05 & $0.01-0.22$ \\
\hline Suicide attempt (yes) & 0.82 & 0.26 & 0.001 & 2.27 & $1.37-3.76$ \\
\hline CASIG adaptation-satisfaction level in friend relationships & -0.16 & 0.05 & $<0.001$ & 0.85 & $0.78-0.93$ \\
\hline STORI: 1-Moratorium (ref: 5-Growth) & 1.39 & 0.41 & 0.001 & 4 & $1.78-8.98$ \\
\hline STORI: 2-Awareness & 1.05 & 0.41 & 0.011 & 2.87 & $1.28-6.44$ \\
\hline STORI: 3-Preparation & 0.67 & 0.43 & 0.12 & 1.95 & $0.84-4.52$ \\
\hline STORI: 4-Rebuilding & 0.38 & 0.38 & 0.318 & 1.47 & $0.69-3.11$ \\
\hline IS Birchwood total score & 0.20 & 0.06 & 0.002 & 1.22 & $1.08-1.38$ \\
\hline WEMWBS (z-score) & -0.26 & 0.12 & 0.037 & 0.77 & $0.60-0.98$ \\
\hline
\end{tabular}

Model chi-squared $(8)=104.1, p<0.001$.

Bold values refer to statistically significant correlations.

European countries (mean IS $=1.94 \mathrm{BD} ; 2.11 \mathrm{MDD}, 21.7 \%$ with moderate-high self-stigma [3]) and Turkey (mean IS $=2.10 \mathrm{BD}$, $18.5 \%)$ [58]. Self-stigma in BD was comparable to the results of a U.S. study with nonadherent patients (mean IS $=2.22 ; 26 \%$ [59]). Self-stigma in anxiety disorders was higher than in the Czech Republic (mean IS $=2.24$ [22]; mean IS $=1.98$ [20]). There are several potential explanations of this higher prevalence of selfstigma. The subsamples of patients with MDD or anxiety disorders were small in size $(n=27 ; n=19)$ and may not be representative. A significant proportion of patients with mood disorders included in the REHABase network had comorbid personality (14\% in BD; $21 \%$ in MDD) or anxiety disorders ( $8 \%$ in $\mathrm{BD}, 12 \%$ in MDD [32]). In addition, the proportion of patients working in mainstream environments was very low in the REHABase network [32] compared with employment rates in $\mathrm{BD}(40-60 \%$ [60]). It can therefore be supposed that the patients with mood disorders referred to the centers for psychiatric rehabilitation had more severe psychiatric comorbidities and were more self-stigmatized than the average. The prevalence of elevated self-stigma in BPD was high, in line with other studies (mean IS = 2.45 [20]; mean IS = 2.37 [23]). Self-stigma in ASD was more frequent than in a recent German study (mean IS $=1.93,15.4 \%$ [21]). This might be related to the levels of public stigma towards ASD in France [1]. Self-stigma should be more systematically investigated in patients with BPD or ASD [20,21].

Few socio-demographic and illness-related variables significantly predicted the level of self-stigma in our sample. The correlations with female gender and older age at the time of admission concur with certain studies [61-63] but contradict others $[20,29]$. According to some authors, tertiary education and employment could protect against self-stigma $[2,3,61,62,64]$. This was not the case in our sample, and this is consistent with other studies $[59,65]$. The absence of a correlation between self-stigma, housing status and intimate relationships corresponds to the findings of most studies on self-stigma [19]. Self-stigma was not associated with parenting status, in contrast to previous research [24]. Higher insight into illness significantly predicted the level of self-stigma, in accordance with several studies $[11,66]$. A history of suicide attempt was associated with elevated self-stigma as found in other studies $[67,68]$. As self-stigma moderates the relationship between insight into illness and depression, it can be supposed that recoveryoriented interventions targeting self-stigma reduction could protect against depression and suicidal ideation and should be further developed $[13,14]$. Illness duration and the number of psychiatric hospitalizations also predicted self-stigma. This concurs with the findings of some studies [60 but contradicts others [5,65]. Age of onset did not predict self-stigma, as in the majority of previous studies $[5,59,65]$. Psychiatric diagnosis did not predict the level of self-stigma, which is consistent with a large number of studies $[27,28,58,64]$. This contrasts with other studies, which found that self-stigma was higher in SZ [61,69], in MDD compared with BD [3], or in BPD compared with other SMI $[20,22,29]$. This study was the first to compare self-stigma in SMI and ASD. Elevated selfstigma was less frequent in ASD, but the mean self-stigma scores did not differ significantly from SMI. Considering the small number of articles on self-stigma in ASD, further research should investigate the relationships between public stigma, perceived stigma, experienced stigma, and self-stigma in ASD. The absence of correlation among neurocognition, social cognition, and selfstigma in our sample was unexpected, as cognitive impairments have been found to be negatively associated with self-stigma in previous studies [15-17,70]. Changes in cognition have been related to functional improvements [71]. Further research should investigate whether improvements in neurocognition and social cognition during psychiatric rehabilitation lead to a reduction in self-stigma. Elevated self-stigma was negatively associated with wellbeing and satisfaction with interpersonal relationships. This concurs with several studies, self-stigma being associated with decreased wellbeing and life satisfaction [72,73]. Self-stigma was consistently negatively associated with QoL in a large body of literature (27 studies [19]). A strong positive correlation was found between self-stigma and the early stages of personal recovery. This reflects the findings of several studies showing a negative association between self-stigma and personal recovery [10,17] (15 studies [19]). The associations between preserved insight into illness, elevated self-stigma, and the early stages of personal recovery in our sample consistently support many of the predictions of the "illnessidentity model" [6].

In short, self-stigma was highly prevalent in a large nonselected sample of people with SMI and ASD enrolled in psychiatric rehabilitation. The correlations between self-stigma, insight, previous suicide attempt, wellbeing, satisfaction with interpersonal relationships, and personal recovery indicate the need to further develop recovery-oriented interventions targeting self-stigma. The effectiveness of psychiatric rehabilitation on self-stigma and the 
potential mediating role of changes in self-stigma on treatment outcomes should be further investigated.

\section{Limits}

Although the REHABase network covers a large proportion of the French territory, it cannot be definitively asserted that its database constitutes a representative sample of the French population of SMI and ASD patients. The REHABase database is composed of participants enrolled in psychiatric rehabilitation and might therefore not be representative of all patients with SMI or ASD. However, some sample characteristics (including sex ratio, age at illness onset, comorbidities) suggest that the present sample is comparable to the general community-dwelling SMI population.

\section{Strengths}

The present study has some clear strengths: a large nonselected sample of community-dwelling SMI and ASD outpatients, the use of a large bundle of standardized evaluation scales, and the inclusion of a large number of potential confounding factors in the multivariate analysis.

Conflict of Interest. The authors declare no conflict of interests.

Acknowledgments. This work was funded by Auvergne-Rhône-Alpes and Nouvelle-Aquitaine regional health agencies. The authors thank Kim Barrett for editorial assistance; Emmanuel Gauthier and Mara Conil for data management; and the members of the REHABase Network (the following teams have all participated in developing the study: C2RL, Limoges; C2RP, Bordeaux; C3R, Grenoble; CL3R, Lyon; CREATIV \& URC Pierre Deniker, Poitiers; and REHALise, Saint-Etienne). The funding source played no role in the creation of the database or the analysis and interpretation of data.

\section{References}

[1] Durand-Zaleski I, Scott J, Rouillon F, Leboyer M. A first national survey of knowledge, attitudes and behaviours towards schizophrenia, bipolar disorders and autism in France. BMC Psychiatry. 2012;12:128.

[2] Brohan E, Elgie R, Sartorius N, Thornicroft G, GAMIAN-Europe Study Group. Self-stigma, empowerment and perceived discrimination among people with schizophrenia in 14 European countries: the GAMIANEurope study. Schizophr Res. 2010;122(1-3):232-238.

[3] Brohan E, Gauci D, Sartorius N, Thornicroft G, GAMIAN-Europe Study Group. Self-stigma, empowerment and perceived discrimination among people with bipolar disorder or depression in 13 European countries: the GAMIAN-Europe study. J Affect Disord. 2011;129(1-3):56-63.

[4] Corrigan PW, Watson AC. Understanding the impact of stigma on people with mental illness. World Psychiatry. 2002;1(1):16-20.

[5] West ML, Yanos PT, Smith SM, Roe D, Lysaker PH. Prevalence of internalized stigma among persons with severe mental illness. Stigma Res Action. 2011;1(1):3-10.

[6] Yanos PT, Roe D, Markus K, Lysaker PH. Pathways between internalized stigma and outcomes related to recovery in schizophrenia spectrum disorders. Psychiatr Serv. 2008;59(12):1437-1442.

[7] Gerlinger G, Hauser M, De Hert M, Lacluyse K, Wampers M, Correll CU. Personal stigma in schizoprhenia spectrum disorders: a systematic review of prevalence rates, correlates, impact and interventions. Word Psychiatry. 2013;12:155-164.

[8] Corrigan PW, Larson JE, Rüsch N. Self-stigma and the "why try" effect: impact on life goals and evidence-based practices. World Psychiatry. 2009; 8:75-81.
[9] Xu Z, Lay B, Oexle N, Drack T, Bleiker M, Lengler S, et al. Involuntary psychiatric hospitalisation, stigma stress and recovery: a 2-year study. Epidemiol Psychiatr Sci. 2018;31:1-8.

[10] Oexle N, Müller M, Kawohl W, Xu Z, Viering S, Wyss C, et al. Self-stigma as a barrier to recovery: a longitudinal study. Eur Arch Psychiatry Clin Neurosci. 2018;268:209-212.

[11] Schrank B, Amering M, Hay AG, Weber M, Sibitz I. Insight, positive and negative symptoms, hope, depression and self-stigma: a comprehensive model of mutual influences in schizophrenia spectrum disorders. Epidemiol Psychiatr Sci. 2014;23(3):271-279.

[12] Park SG, Bennett ME, Couture SM, Blanchard JJ. Internalized stigma in schizophrenia: relations with dysfunctional attitudes, symptoms, and quality of life. Psychiatry Res. 2013;205(1-2):43-47.

[13] Lysaker PH, Roe D, Yanos PT. Toward understanding the insight paradox: internalized stigma moderates the association between insight and social functioning, hope, and self-esteem among people with schizophrenia spectrum disorders. Schizophr Bull. 2007;33(1):192-199.

[14] Lysaker PH, Vohs J, Hasson-Ohayon I, Kukla M, Wierwille J, Dimaggio G. Depression and insight in schizophrenia: comparisons of levels of deficits in social cognition and metacognition and internalized stigma across three profiles. Schizophr Res. 2013;148(1-3):18-23.

[15] Lysaker PH, Buck KD, Taylor AC, Roe D. Associations of metacognition and internalized stigma with quantitative assessments of self-experience in narratives of schizophrenia. Psychiatry Res. 2008;157(1-3):31-38.

[16] Lysaker PH, Vohs JL, Tsai J. Negative symptoms and concordant impairments in attention in schizophrenia: associations with social functioning, hope, self-esteem and internalized stigma. Schizophr Res. 2009;110(1-3): 165-172.

[17] Hasson-Ohayon I, Mashiach-Eizenberg M, Elhasid N, Yanos PT, Lysaker $\mathrm{PH}$, Roe D. Between self-clarity and recovery in schizophrenia: reducing the self-stigma and finding meaning. Compr Psychiatry. 2014;55(3): 675-680.

[18] Livingston JD, Boyd JE. Correlates and consequences of internalized stigma for people living with mental illness: a systematic review and meta-analysis. Soc Sci Med. 2010;71(12):2150-2161.

[19] Dubreucq J, Franck N. Internalized Stigma in Serious Mental Illness (SMI): a systematic review of prevalence, predictors and correlates. J. Affect. Disord [submitted].

[20] Grambal A, Prasko J, Kamaradova D, Latalova K, Holubova M, Marackova $\mathrm{M}$, et al. Self-stigma in borderline personality disorder-cross-sectional comparison with schizophrenia spectrum disorder, major depressive disorder and anxiety disorders. Neuropsychiatr Dis Treat. 2016;12:2439-2448.

[21] Bachmann CJ, Höfer J, Kamp-Becker I, Küpper C, Poustka L, Roepke S, et al. Internalised stigma in adults with autism: a German multi-center survey. Psychiatry Res. 2019;276:94-99.

[22] Ociskova M, Prasko J, Kamaradova D, Grambal A, Sigmundova Z. Individual correlates of self-stigma in patients with anxiety disorders with and without comorbidities. Neuropsychiatr Dis Treat. 2015;11:1767-1779.

[23] Kamaradova D, Latalova K, Prasko J, Kubinek R, Vrbova K, Mainerova B, et al. Connection between self-stigma, adherence to treatment and discontinuation of medication. Patient Prefer Adherence. 2016;10: 1289-1298.

[24] Lacey M, Paolini S, Hanlon MC, Melville J, Galletly C, Campbell LE. Parents with serious mental illness: differences in internalized and externalized mental illness stigma and gender stigma between mothers and fathers. Psychiatry Res. 2015;225(3):723-733.

[25] Young DK, Ng PY. The prevalence and predictors of self-stigma of individuals with mental health illness in two Chinese cities. Int J Soc Psychiatry. 2016;62(2):176-185.

[26] Sibitz I, Provaznikova K, Lipp M, Lakeman R, Amering M. The impact of recovery-oriented day clinic treatment on internalized stigma: preliminary report. Psychiatry Res. 2013;209(3):326-332.

[27] Rüsch N, Nordt C, Kawohl W, Brantschen E, Bärtsch B, Müller M, et al. Work-related discrimination and change in self-stigma among people with mental illness during supported employment. Psychiatr Serv. 2014; 65:1496-1498.

[28] Harris JI, Farchmin L, Stull L, Boyd J, Schumacher M, Drapalski AL. Prediction of changes in self-stigma among veterans participating in 
partial psychiatric hospitalization: the role of disability status and military cohort. Psychiatr Rehabil J. 2015;38(2):179-185.

[29] Pearl RL, Forgeard MJC, Rifkin L, Beard C, Björgvinsson T. Internalized stigma of mental illness: changes and associations with treatment outcomes. Stigma Health. 2017;2(1):2-15.

[30] Yanos PT, Roe D, West ML, Smith SM, Lysaker PH. Group-based treatment for internalized stigma among persons with severe mental illness: findings from a randomized controlled trial. Psychol Serv. 2012;9(3): 248-258.

[31] Bouvet C, Bouchoux A. Exploring the relationship between internalized stigma, insight and depression for inpatients with schizophrenia. Encephale. 2015;41:435-443.

[32] Franck N, Bon L, Dekerle M, Plasse J, Massoubre C, Pommier R, et al. Satisfaction and needs in serious mental illness and autism spectrum disorder: the REHABase psychosocial rehabilitation project. Psychiatr Serv. 2019;70(4):316-323.

[33] Substance Abuse and Mental Health Services Administration (SAMHSA). Results from the 2013 National Survey on Drug Use and Health: Mental Health Findings. NSDUH Series H-49, HHS Publication No. (SMA) 14-4887. Rockville, MD: Substance Abuse and Mental Health Services Administration, 2014.

[34] American Psychiatric Association. Diagnostic And Statistical Manual Of Mental Disorders, fifth edition (DSM-5). Washington, DC: Author, 2013.

[35] Jääskeläinen E, Juola P, Hirvonen N, McGrath JJ, Saha S, Isohanni M, et al. A systematic review and meta-analysis of recovery in schizophrenia. Schizophr Bull. 2013;39:1296-1306.

[36] Boyd Ritsher J, Otilingam PG, Grajales M. Internalized Stigma of Mental Illness: psychometric properties of a new measure. Psychiatry Res. 2003; 121:31-49.

[37] Yanos PT, Lysaker PH, Silverstein SM, Vayshenker B, Gonzales L, West $\mathrm{ML}$, et al. A randomized-controlled trial of treatment for self-stigma among persons diagnosed with schizophrenia-spectrum disorders. Soc Psychiatry Psychiatr Epidemiol. 2019;54(11):1363-1378. https://oi. org/10.1007/s00127-019-01702-0.

[38] Wallace CJ, Lecomte T, Wilde J, Liberman RP. CASIG: a consumercentered assessment for planning individualized treatment and evaluating program outcomes. Schizophr Res. 2001;50(1-2):105-119.

[39] Kay S, Fiszbein A, Opler L. The positive and negative syndrome scale (PANSS) for schizophrenia. Schizophr Bull. 1987;13(2):261-276

[40] Haro JM, Kamath SA, Ochoa S, Novick D, Rele K, Fargas A, et al. The Clinical Global Impression-schizophrenia scale: a simple instrument to measure the diversity of symptoms present in schizophrenia. Acta Psychiatr Scand. 2003;107(416):16-23.

[41] Birchwood M, Smith J, Drury V, Healy J, Macmillan F, Slade M. A selfreport Insight Scale for psychosis: reliability, validity and sensitivity to change. Acta Psychiatr Scand. 1994;89(1):62-67.

[42] Thompson K, Kulkarni J, Sergejew AA. Reliability and validity of a new Medication Adherence Rating Scale (MARS) for the psychoses. Schizophr Res. 2000;42(3):241-247.

[43] Startup M, Jackson MC, Bendix S. The concurrent validity of the Global Assessment of Functioning (GAF). Br J Clin Psychol. 2002;41(Pt 4): 417-422.

[44] Auquier P, Simeoni MC, Sapin C, Reine G, Aghababian V, Cramer J, et al. Development and validation of a patient-based health-related quality of life questionnaire in schizophrenia: the S-QoL. Schizophr Res. 2003;63(12):137-149.

[45] Tennant R, Hiller L, Fishwick R, Stephen P, Stephen J, Scott W, et al. The Warwick-Edinburgh Mental Well-being Scale 19 (WEMWBS): development and UK validation. Health Qual Life Outcomes. 2007;5:63.

[46] Lecomte $\mathrm{T}$, Corbière $\mathrm{M}$, Laisné $\mathrm{F}$. Investigating self-esteem in individuals with schizophrenia: relevance of the Self-Esteem Rating Scale-Short Form. Psychiatry Res. 2006;143(1):99-108.

[47] Andresen R, Caputi P, Oades LG. Stages of recovery instrument: development of a measure of recovery from serious mental illness. Aust NZ J Psychiatry. 2006;40:972-980.

[48] Wechsler D. WAIS IV Nouvelle version de l'échelle d'intelligence de Weschler pour adultes. 4ème édition. Paris, France: Edition de Centre de Psychologie Appliquée, 2011.
[49] Delis DC, Freeland J, Kramer JH, Kaplan E. Integrating clinical assessment with cognitive neuroscience: construct validation of the California Verbal Learning Test. J Consult Clin Psychol. 1988;56(1):123-130.

[50] Van der Linden M, Coyette F, Poitrenaud J, Béatrice D, Bernard D, AnneMarie E, et al. (2004) L'épreuve de rappel libre/rappel indice à 16 items (RL/RI-16). In: L'Évaluation Des Troubles de La Mémoire: Présentation de Quatre Tests de Mémoire Épisodique Avec Leur Étalonnage. pp 25-47.

[51] Brickenkamp R, Schmidt-Atzert L, Liepmann A. D. D2-R: Test d'attention concentrée révisé. Paris, France: Editions Hogrefe, 2015.

[52] Fournet N, Demazière-Pelletier Y, Favier S, Lemoine L, Gros C (2015). Test des Commissions révisé. In: "GREMOIRE2 tests et échelles des maladies neurologiques avec symptomatologie cognitive," sous la direction de L Hugonot-Diener, C Thomas-Anthérion \& F Sellal, éditions De Boeck-Solal, Louvain-Paris, p. 70-74.

[53] Shallice T, Burgess PW. Deficits in strategy application following frontal lobe dama-ge in man. Brain. 1991;114(2):727-741.

[54] Dziobek I, Fleck S, Kalbe E, Rogers K, Hassenstab J, Brand M, et al. Introducing MASC: a movie for the assessment of social cognition. J Autism Dev Disord. 2006;36(5):623-636.

[55] Combs DR, Penn DL, Wicher M, Waldheter E. The Ambiguous Intentions Hostility Questionnaire (AIHQ): a new mesure for evaluating hostile social-cognitive biases in paranoia. Cogn Neuropsychiatry. 2007;12(2) 128-143.

[56] R Core Team. (2015) R: A Language and Environment for Statistical Computing, R Foundation for Statistical Computing, Vienna, Austria.

[57] Caqueo-Urízar A, Boyer L, Urzúa A, Williams DR. Self-stigma in patients with schizophrenia: a multicentric study from three Latin-America countries. Soc Psychiatry Psychiatr Epidemiol. 2019.

[58] Sarısoy G, Kaçar ÖF, Pazvantoğlu O, Korkmaz IZ, Öztürk A, Akkaya D, et al. Internalized stigma and intimate relations in bipolar and schizophrenic patients: a comparative study. Compr Psychiatry. 2013;54: 665-672.

[59] Howland M, Levin J, Blixen C, Tatsuoka C, Sajatovic M. Mixed-methods analysis of internalized stigma correlates in poorly adherent individuals with bipolar disorder. Compr Psychiatry. 2016;70:174-180.

[60] Marwaha S, Durrani A, Singh S. Employment outcomes in people with bipolar disorder: a systematic review. Acta Psychiatr Scand. 2013;128(3): 179-193.

[61] Krajewski C, Burazeri G, Brand H. Self-stigma, perceived discrimination and empowerment among people with a mental illness in six countries: Pan European stigma study. Psychiatry Res. 2013;210:1136-1146.

[62] Livingston J, Patel N, Bryson S, Hoong P, Lal R, Morrow M, et al. Stigma associated with mental illness among Asian men in Vancouver, Canada. Int J Soc Psychiatry. 2018;64:679-689.

[63] Ho RWH, Chang WC, Kwong VWY, ESK L, GHK C, OTT J, et al. Prediction of self-stigma in early psychosis: 3-year follow-up of the randomized-controlled trial on extended early intervention. Schizophr Res. 2018;195:463-468.

[64] Evans-Lacko S, Brohan E, Mojtabai R, Thornicroft G. Association between public views of mental illness and self-stigma among individuals with mental illness in 14 European countries. Psychol Med. 2012;42:1741-1752.

[65] Sibitz I, Amering M, Unger A, Seyringer ME, Bachmann A, Schrank B, et al. The impact of the social network, stigma and empowerment on the quality of life in patients with schizophrenia. Eur Psychiatry. 2011;26: 28-33.

[66] Hasson-Ohayon I, Ehrlich-Ben Or S, Vahab K, Amiaz R, Weiser M, Roe D. Insight into mental illness and self-stigma: the mediating role of shame proneness. Psychiatry Res. 2012;200:802-806.

[67] Yoo T, Kim SW, Kim SY, Lee JY, Kang HJ, Bae KY, et al. Relationship between suicidality and low self-esteem in patients with schizophrenia. Clin Psychopharmacol Neurosci. 2015;13:296-301.

[68] Chang CC, Wu TH, Chen CY, Lin CY. Comparing self-stigma between people with different mental disorders in Taiwan. J Nerv Ment Dis. 2016; 204:547-553.

[69] Kao YC, Lien YJ, Chang HA, Wang SC, Tzeng NS, Loh CH, et al. Evidence for the indirect effects of perceived public stigma on psychosocial outcomes: the mediating role of self-stigma. Psychiatry Res. 2016;240: $187-195$. 
[70] Galderisi S, Rossi A, Rocca P, Bertolino A, Mucci A, Bucci P, et al. The influence of illness-related variables, personal resources and contextrelated factors on real-life functioning of people with schizophrenia. World Psychiatry. 2014;13(3):275-287.

[71] Green MF, Horan WP, Lee J. Nonsocial and social cognition in schizophrenia: current evidence and future directions. World Psychiatry. 2019; 18(2):146-161.
[72] Rüsch N, Corrigan PW, Heekeren K, Theodoridou A, Dvorsky D, Metzler S. Well-being among persons at risk of psychosis: the role of self-labeling, shame, and stigma stress. Psychiatr Serv. 2014;65:483-489.

[73] Pérez-Garín D, Molero F, Bos AE. Internalized mental illness stigma and subjective well-being: The mediating role of psychological well-being. Psychiatry Res. 2015;228:325-331. 